\title{
Dual Action of a Carbohydrate Epitope on Afferent and Efferent Axons in Cortical Development
}

\author{
Sigrid Henke-Fahle, ${ }^{1}$ Fanny Mann,, ${ }^{2}$ Magdalena Götz, ${ }^{3}$ Karen Wild, ${ }^{3}$ and Jürgen Bolz ${ }^{2,3}$ \\ ${ }^{1}$ Department of Ophthalmology, University of Tübingen, Tübingen, Germany, 2Institut National de la Santé et de la \\ Recherche Médicale Unité 371 Cerveau et Vision, Bron, France, and ${ }^{3}$ Friedrich-Miescher-Labor der Max-Planck- \\ Gesellschaft, Tübingen, Germany
}

\begin{abstract}
During development of the mammalian cerebral cortex, ingrowing afferents from the thalamus take a path that is different from that of axons leaving the cortical plate. Thalamic axons arrive at the cortex at the time before their target cells of layer 4 are generated in the ventricular zone, but they invade the cortex only shortly before these cells have migrated to their final position in the cortex. Growth-promoting molecules are upregulated in the developing cortical plate during this period. To identify such molecules, we have generated monoclonal antibodies against membrane preparations from rat postnatal cortex. In Western blots, one antibody (mAb 10) recognized a carbohydrate epitope of a glycoprotein with an apparent molecular weight extending from 180 to $370 \mathrm{kDa}$. Immunohistochemical staining revealed that the staining pattern of $\mathrm{mAb} 10$ at embryonic stages delineates the pathway of thalamocortical axons, with only very faint labeling of the corticofugal pathway. In vitro assays in combination with time-lapse imaging indi-
\end{abstract}

cated that mAb 10 has opposite effects on the growth of thalamic and cortical axons. The growth speed and axonal elongation of thalamic fibers on postnatal cortical membranes preincubated with mAb 10 was reduced compared with untreated cortical membranes. In contrast, cortical axons grew faster and stopped their growth less frequently after addition of mAb 10 to a cortical membrane substrate. Taken together, these results suggest that a carbohydrate moiety of a membrane-associated glycoprotein plays a role in the segregation of afferent and efferent cortical axons in the white matter. Moreover, the epitope recognized by mAb 10 might also contribute to regulation of the timing of the thalamocortical innervation at later developmental stages.

Key words: cortical development; thalamocortical connections; segregation of afferent and efferent cortical projections; axonal growth rate; extracellular matrix; carbohydrate epitope; monoclonal antibodies; time-lapse imaging
During development, the guidance of axons to their targets is controlled by molecules in the environment of the growth cone. These are either diffusible factors or constituents of the cell surface and the extracellular matrix (Bixby and Harris, 1991; Goodman and Shatz, 1993; Lander, 1993). Receptors on the axonal growth cone mediate the recognition of guidance molecules, leading to changes in the cytoskeleton of the growth cone and influencing the orientation of axons (Lin et al., 1994). The response of the neuron to a given substrate is also thought to be dependent on the spatial context in which it is presented. Whether the molecule is distributed as a uniform substrate, a sharp boundary, or a gradient can determine the behavior of the neurite (Walter et al., 1987b; Baier and Bonhoeffer, 1992; Lochter and Schachner, 1993). Axonal subpopulations may respond to a changing environment by expressing different sets of receptors and adhesion molecules (Dodd et al., 1988; De Curtis et al., 1991).

In developing neocortex, thalamic afferents follow a pathway that is distinct from the adjacent pathway taken by axons leaving

\footnotetext{
Received Nov. 10, 1995; revised April 8, 1996; accepted April 12, 1996.

This work was supported in part by the Deutsche Forschungsgemeinschaft (He1514/2-1). We thank Iris Kehrer for her help with the histology and the antibody screening, Dominique Bagnard for help with the analysis of time-lapse recordings, and Bernhard Müller for comments on this manuscript.

Correspondence should be addressed to Jürgen Bolz, Institut National de la Santé et de la Recherche Médicale Unité 371 Cerveau et Vision, 18 Avenue du Doyen Lépine, 69500 Bron, France.

Magdalena Götz's present address: SmithKline Beecham, Harlow, UK.

Karen Wild's present address: Sektion Sensorische Biophysik, University of Tübingen, Tübingen, Germany.

Copyright (C) 1996 Society for Neuroscience $0270-6474 / 96 / 164195-12 \$ 05.00 / 0$
}

the cortex (De Carlos and O'Leary, 1992; Bicknese et al., 1994). Afferent and efferent fibers also differ in their ability to respond to growth-promoting molecules in the cortex. Although rat cortical axons grow on a membrane preparation from either embryonic or postnatal cortex, thalamic axons tend to avoid an embryonic cortical explant and show poor outgrowth on embryonic membranes (Götz et al., 1992). This behavior reflects the situation in vivo. In several mammalian species, it has been demonstrated that fibers from the thalamus arrive before the generation of their cortical target neurons in layer 4 (Lund and Mustari, 1977; Rakic, 1977; Shatz and Luskin, 1986; Catalano et al., 1991; Ghosh and Shatz, 1992; Götz et al., 1992; Kageyama and Robertson, 1993; Miller at al., 1993). Thalamic axons are confined first to the subplate zone beneath the developing cortical layers and enter the cortical gray matter only after layer 4 cells have migrated to their final position. This time delay between arrival of thalamic fibers and formation of their target layer is short in rodents but can cause a waiting period of up to 2 months in the developing human cortex (Kostovic and Rakic, 1990).

The mechanisms that regulate the timing of afferent cortical innervation are not understood completely. In vitro experiments indicated that membrane-associated molecules promoting the growth of thalamic fibers are upregulated in the cortex in parallel with its innervation by thalamic axons (Götz et al., 1992; Bolz et al., 1993; Hübener et al., 1995; Tuttle et al., 1995). As a first attempt to characterize such molecules, we generated monoclonal antibodies (mAb) against postnatal cortical membranes. We describe here three antibodies binding to antigens whose expression 
patterns correlate with cortical invasion by thalamic fibers. One antibody (mAb 10) proved to be especially interesting, because its staining revealed a molecular heterogeneity in the intermediate zone. The biochemical analysis indicated that mAb 10 recognizes a carbohydrate epitope of a matrix-bound glycoprotein. In vitro assays showed that this antibody interferes with the outgrowth of thalamic and cortical axons in an opposing fashion, i.e., it inhibits growth of thalamic axons on a cortical membrane substrate, but at the same time enhances growth of cortical axons. The spatiotemporal distribution and the dual mechanism on axonal elongation of this epitope suggests that it might be involved in regulating the cortical invasion of thalamic axons as well as in segregating afferent and efferent projections in the developing white matter.

A preliminary report of some of these findings has been presented in abstract form (Henke-Fahle et al., 1994).

\section{MATERIALS AND METHODS}

Generation of $m A b s$. Six-week-old female Balb/c mice were immunized with membrane preparations from postnatal day 6 (P6) rat cortex (Lewis strain) suspended in RAS (Ribi's-Adjuvans-System; Pan Systems). Mice were injected intraperitoneally at biweekly intervals $4 \mathrm{~d}$ after the last boost spleen cells were fused with NS-1 hybridoma cells, according to established methods (Fazekas de St. Groth and Scheidegger, 1980), and distributed into 96-multiwell dishes containing a feeder layer of peritoneal macrophages. Hybridoma supernatants were screened on fixed frozen sections of embryonic day 16 (E16), E19, and P6 cortex from Lewis rats $($ day of sperm detection $=\mathrm{E} 1)$. Cell lines of interest were subcloned several times by limiting dilution.

Immunohistochemistry. Brains were removed, immediately frozen on dry ice, and cut on a cryostat at a thickness of $10 \mu \mathrm{m}$. Frontal sections from presumptive sensorimotor cortex were fixed for $10 \mathrm{~min}$ in ice-cold methanol and washed several times in PBS. Incubation with tissue culture supernatants was carried out overnight at $4^{\circ} \mathrm{C}$. Unbound antibody was washed off with PBS, and the sections were then incubated with rhodamin-coupled rabbit-anti-mouse $\operatorname{IgG}+\operatorname{IgM}(1: 250$; Jackson ImmunoResearch Labs, West Grove, PA). Alternatively, for immunostaining with $\mathrm{mAb} 10$, sections were incubated with biotinylated rabbitanti-mouse IgM (1:200; Vector Labs, Burlingame, CA), briefly washed with PBS, and then incubated with Cy3-conjugated streptavidin (1:100; Amersham, Buckinghamshire, UK). With this more sensitive detection method, the tissue culture supernatant was diluted 1:20, which considerably decreased the background staining without significantly reducing the specific antibody staining. To label cell nuclei, sections were counterstained with bisbenzimide solution $(1 \mu \mathrm{g} / \mathrm{ml}$ in PBS, 5 min at room temperature; Sigma, St. Louis, MO).

Membrane preparation. Membranes were prepared according to Götz et al. (1992). Blocks of cortex were dissected in Gey's balanced salt solution (GBSS) supplemented with glucose $(6.5 \mathrm{mg} / \mathrm{ml})$, and the pia was removed. Slices (thickness, $200-300 \mu \mathrm{m}$ ) were cut with a McIlwain tissue chopper and homogenized in homogenization buffer consisting of $10 \mathrm{mM}$ Tris- $\mathrm{HCl}, 1.5 \mathrm{~mm} \mathrm{CaCl}, 1 \mathrm{~mm}$ spermidine, $25 \mu \mathrm{g} / \mathrm{ml}$ aprotinin, $25 \mu \mathrm{g} / \mathrm{ml}$ leupeptin, $5 \mu \mathrm{g} / \mathrm{ml}$ pepstatin, and $15 \mu \mathrm{g} / \mathrm{ml}$ 2,3-dehydro-2-desoxy- $N$ acetylneuraminic acid (all from Sigma), $\mathrm{pH}$ 7.4. The homogenate was centrifuged for $10 \mathrm{~min}$ at $25,000 \mathrm{rpm}$ in a sucrose step gradient (upper phase $150 \mu \mathrm{l}$ of $5 \%$ sucrose, lower phase $350 \mu \mathrm{l}$ of $50 \%$ sucrose) in a Beckman TLS 55 rotor. The interband containing the membrane fraction was washed twice with PBS without $\mathrm{Ca}^{2+}$ and $\mathrm{Mg}^{2+}$ at $14,000 \mathrm{rpm}$ in an Eppendorf Biofuge, and after resuspension the membrane concentration was determined by its optical density measured with a photospectrometer at $220 \mathrm{~nm}$. The actual protein content was determined according to the method of Bradford (1976). In these cell membrane preparations, molecules from the extracellular matrix co-purify.

Quantitative growth assay. Coverslips $(12 \times 24 \mathrm{~mm})$ were boiled for 10 min in absolute ethanol, air-dried, and then sterilized for $24 \mathrm{hr}$ at $150^{\circ} \mathrm{C}$. Pairs of coverslips were coated with $2 \mu \mathrm{g}$ of laminin (Sigma) in $100 \mu \mathrm{l}$ of GBSS as a "sandwich" for $60 \mathrm{~min}$ at $37^{\circ} \mathrm{C}$ under sterile conditions. The coverslips were then separated, washed with PBS, and air-dried. They were then coated again as a sandwich with $100 \mu \mathrm{l}$ of membrane suspension (optical density 0.1 or 0.2 ) at $37^{\circ} \mathrm{C}$ for $1-2 \mathrm{hr}$. After separation, the coverslips were placed in Petriperm dishes (Bachofer, Reutingen, Germany) with $0.75 \mathrm{ml}$ of culture medium, with or without antibodies. The medium consisted of 50\% Eagle's basal medium, 25\% HBSS, and $25 \%$ horse serum; in addition, $0.1 \mathrm{~mm}$ glutamine, $6.5 \mathrm{mg} / \mathrm{ml}$ glucose, $4 \mathrm{mg} / \mathrm{ml}$ methylcellulose, $100 \mathrm{U} / \mathrm{ml}$ penicillin, $100 \mu \mathrm{g} / \mathrm{ml}$ streptomycin, and 2.5 $\mu \mathrm{g} / \mathrm{ml}$ amphotericin were added. Thalamic or cortical explants were then pipetted onto the coverslips. Explants from E16 rats were prepared from slices of the whole dorsal thalamus or the cortical hemispheres by cutting them into $200 \times 200 \times 200 \mu \mathrm{m}$ pieces with a McIlwain tissue chopper. After $\sim 30 \mathrm{~min}$, most of the explants had adhered to the coated coverslips, and another $1.25 \mathrm{ml}$ of medium was added. Cultures were kept at $37^{\circ} \mathrm{C}$ under $5 \% \mathrm{CO}_{2}$ in air atmosphere.

Antibody-containing tissue culture media were concentrated with either a Filtron-Ultrasette or Filtron-Centricon membranes. Antibodies were added to the culture medium at 5-7 $\mu \mathrm{g} / \mathrm{ml}$. In another series of experiments, membranes were preincubated with the concentrated antibody solution diluted $1: 10$ for $2-4 \mathrm{hr}$ at $4^{\circ} \mathrm{C}$ (resulting concentration 7 $\mu \mathrm{g} / \mathrm{ml}$ ), and the membranes were then used in the test assay. After $2-4 \mathrm{~d}$ in vitro, the explants were fixed with $4 \%$ paraformaldehyde. The number of distal ends of the outgrowing axons was counted using an inverted microscope with phase-contrast optics. To confirm the neuronal origin of the fibers, several explants were stained with antibodies directed against neuronal markers SMI31 (Sternberger and Meyer, Inc.) and MAP5 (Sigma) and glial markers vimentin (Sigma) and GFAP (Bioscience, Bethlehem, PA). Statistical differences between antibody-treated cultures and controls were determined with the unpaired $t$ test.

We also measured the length of cortical and thalamic axons in the presence and absence of $\mathrm{mAb} 10$. For this, several prints from video images of an explant were taken at a final magnification of $120 \times$ to cover the full length of all axons extending from this explant. On these video prints, concentric circles with increasing diameter were drawn; the smallest, innermost circle was fitted by eye to the rim of each explant. The spacing of the circles corresponded to $100 \mu \mathrm{m}$. We then counted the number of distal ends of the axons in each annulus, and in each case we checked under the microscope with a $20 \times$ objective to determine that the axons possessed a well-defined growth cone and exhibited no signs of degeneration. In this way we obtained the total axonal length in multiples of $100 \mu \mathrm{m}$. To illustrate the data, a graphic representation introduced by Chang et al. (1987), which plots the percentage of axons longer than a given length versus axonal length, was used. As a characteristic for the effect of antibody treatment, the " $L_{50}$ value," defined as the length exceeded by $50 \%$ of all axons, was determined from these plots.

Time-lapse video microscopy. For time-lapse imaging, a Petriperm dish containing a coverslip with cortical or thalamic explants was transferred to a closed chamber on the stage of an inverted microscope (Zeiss Axiovert) equipped with phase-contrast optics. Temperature $\left(35^{\circ} \mathrm{C}\right)$ and $\mathrm{CO}_{2}$ concentration $(5 \%)$ were kept constant. Video images were taken every $60 \mathrm{sec}$ with a sensitive CCD camera (Imac). To minimize photo damage, a computer-controlled shutter closed the light path after the images had been captured with an image analysis system (Hamamatsu, Bridgewater, NJ). The images were contrast-enhanced and stored for later analysis on video tape. As reported previously, cultures that had been filmed continuously for $3 \mathrm{~d}$ revealed no differences in growth-rate compared with cultures that were kept in the incubator during this time (Hübener et al., 1995).

The video recordings were analyzed with a Panasonic video editing controller. At every fifth frame (corresponding to 5 min intervals), the positions of the center of the growth cones were marked on a transparent overlay over the video monitor to reconstruct the trajectories of the axons. Only axons that were imaged continuously for at least $90 \mathrm{~min}$ and did not contact other axons during the recording period were analyzed. From these trajectories we determined the mean and maximal growth speed as well as the number and duration of the pauses during axon elongation. We then also calculated the net growth speed, i.e., the average speed during the growth phase of the axons.

Immunoblotting. Cortex from E19 and P6-P7 animals was homogenized in $10 \mathrm{~mm}$ Tris- $\mathrm{HCl}$, and $1.5 \mathrm{mM} \mathrm{CaCl}_{2}, \mathrm{pH} 7.0$, containing protease inhibitors $(50 \mu \mathrm{g} / \mathrm{ml}$ phenylmethylsulfonylfluoride, $25 \mu \mathrm{g} / \mathrm{ml}$ aprotinin, 25 $\mu \mathrm{g} / \mathrm{ml}$ leupeptin, and $5 \mu \mathrm{g} / \mathrm{ml}$ pepstatin). The homogenate was centrifuged for $30 \mathrm{~min}$ in a Sorvall centrifuge at $20,000 \times g$. The sediment was either solubilized directly in sample buffer $(0.1 \mathrm{~m}$ phosphate buffer, $1 \%$ SDS, $10 \%$ glycerol, $0.1 \mathrm{M}$ dithiothreitol; $5 \mathrm{~min}$ at $100^{\circ} \mathrm{C}$ ) or extracted with $6 \mathrm{M}$ urea in PBS on ice, cleared by centrifugation for $50 \mathrm{~min}$ at $105,000 \times$ $g$; the supernatant was dialyzed against two changes of $10 \mathrm{~mm}$ phosphate buffer and $0.1 \mathrm{M} \mathrm{NaCl}, \mathrm{pH} 7.0$. Protein $(70 \mu \mathrm{g}$ each) was digested with 40 $\mathrm{mU}$ of the enzymes chondroitinase $\mathrm{ABC}$, chondroitinase $\mathrm{AC}$, heparitinase, and keratinase (all from Sigma; protease-free chondroitinase $A B C$ also from ICN and from Boehringer Mannheim, Mannheim, Germany) 
overnight at $37^{\circ} \mathrm{C}$ in the presence of protease inhibitors as above and 5 mM EDTA. Incubation with PNGaseF (BioLabs) was according to the instructions of the manufacturer. Digested samples and controls kept at $37^{\circ} \mathrm{C}$ were applied to $7 \%$ and $10 \%$ SDS-PAGE gels and run under reducing conditions in Laemmli buffer. Transfer onto nitrocellulose filters (BA85; Schleicher \& Schüll, Keene, NH) was carried out for $4 \mathrm{hr}$ at $20 \mathrm{~V}$ in Laemmli buffer containing $0.0001 \%$ SDS. Filters were blocked with $5 \%$ nonfat dry milk in PBS ( $1 \mathrm{hr}, \mathrm{RT})$ and incubated overnight at $4^{\circ} \mathrm{C}$ with hybridoma supernatants diluted 1:1 with washing buffer (PBS with $0.1 \%$ Tween 20). Bound antibody was visualized by reaction with peroxidaselabeled goat-anti-mouse IgG + IgM (Jackson ImmunoResearch) for $1 \mathrm{hr}$ at RT and subsequent development with chloronaphthol $/ \mathrm{H}_{2} \mathrm{O}_{2}$. Dot blots were performed by filtrating $100 \mu \mathrm{l}$ of a protein solution $(1 \mathrm{mg} / \mathrm{ml}$ protein concentration) onto a nitrocellulose membrane by means of a dot-blot apparatus (Millipore).

\section{RESULTS}

mAbs were generated using a membrane preparation from $\mathrm{P} 6$ rat cortex that supports thalamic fiber outgrowth in vitro. Hybridoma supernatants were tested on cryostat sections from E16, E19, and P6 cortex to detect antibodies specifically binding to components that are regulated developmentally. Because we attempted to identify candidates of membrane-associated proteins that play a role during the development of thalamocortical projections, we screened for mAbs whose spatiotemporal staining pattern corresponded closely to the thalamocortical invasion. Of $>7000$ hybridoma cell lines tested, four cell lines fulfilled this criterion, and three of these cell lines (mAbs 10, 111, and 942) were stably established and their antibodies were analyzed in more detail.

\section{Developmental expression of antigens 10, 111, and 942}

Axons arising from neurons in the thalamus pass through the internal capsule and then enter the lateral wall of the telencephalon at approximately E16. Once within the neocortex, the pathway of thalamocortical axons is centered on the subplate and the upper part of the intermediate zone. The fibers reach the dorsomedial aspect of the telencephalon by E17. At this stage, faint staining with all three antibodies can be detected in the subplate region (data not shown). By E19, the antibodies strongly stain the subplate and intermediate zone. The cortical plate and the ventricular zone display little but discernible label, whereas the fiberrich marginal zone is clearly stained. At P6, prominent antigen is visible in all cortical layers (Fig. 1). The location of all three antigens within the tissue seems to be indicative of extracellular matrix components. The cell membranes, if positive, do not stand out as particularly more stained than the surrounding matrix; however, the exact location can be determined only at the electron microscopic level.

There are, however, distinct differences in the staining patterns between the three different antibodies. The most notable differences are between mAb 10 and the other antibodies, mAbs 111 and 942. At E19, labeling with mAb 10 was inhomogeneous in the intermediate zone, with very little expression in the lower part adjoining the ventricular zone. In contrast, mAbs 111 and 942 strongly stained throughout the intermediate zone (Fig. 1). Moreover, there was a clear mediolateral gradient in the distribution of the mAb 10 epitope at E19. In the medial regions, labeling was restricted to the subplate zone, and in more lateral regions $\mathrm{mAb}$ 10 staining spread into the upper part of the intermediate zone (Fig. 2). Finally, with mAb 10, there was also faint staining within the subventricular zone.

\section{Functional assays}

Because of the close correlation between cortical invasion by thalamic fibers and the staining pattern of all three antibodies, we tested their ability to interfere with the growth of thalamic as well as cortical axons. Various in vitro test situations were used to analyze their influence on axonal growth.

In the first experimental paradigm, a membrane preparation from early postnatal cortex was offered as substrate, and outgrowth of fibers from E16 thalamic and cortical explants was determined in the presence of antibodies and compared with the values obtained without antibody addition. Cortical membranes from postnatal days 2-7 were used, because thalamic explants had shown dense fiber extension in a quantitative growth assay using membranes from these developmental stages (Götz et al., 1992). Figure 3 illustrates axonal outgrowth from thalamic and cortical explants on $\mathrm{P} 4$ cortical membranes after $4 \mathrm{~d}$ in vitro under control conditions (Fig. $3 A, C$ ) and after addition of $6 \mu \mathrm{g} / \mathrm{ml} \mathrm{mAb} 10$ to the culture medium (Fig. $3 B, D$ ). mAb 10 exerted a differential effect on the growth of thalamic and cortical axons: it diminished the number of fibers extending from thalamic explants and enhanced fiber outgrowth from cortical explants. On average, the presence of $\mathrm{mAb} 10$ reduced the outgrowth from thalamic explants to $<50 \%$ of the control value ( $p<0.001, n=357$ explants; Fig. $4 A)$ and enhanced cortical outgrowth to $139 \%(p<0.01, n=$ 351 explants; Fig. $4 C$ ). In the same test situation but using the EHS tumor-derived laminin as a substrate, there was no significant influence of mAb 10 on thalamic and cortical fiber extension (Fig. 4B,D). The mAb 942 did not exert a significant effect on either fiber subpopulation, independent of whether it was tested on membranes (Fig. $4 A, C$ ) or laminin (Fig. $4 B, D$ ). Because this antibody belongs to the same immunoglobulin class as mAb 10 (IgM), we take this result as evidence that the addition of an antibody solution as such does not interfere with axonal growth. Fiber extension in the presence of $7 \mu \mathrm{g} / \mathrm{ml} \mathrm{mAb} 111$ (IgG) was reduced for thalamic explants on cortical membranes $(p<0.01$; Fig. $4 A$ ), but remained unchanged with cortical axons (Fig. $4 C$ ) and when laminin was used as substrate (Fig. 4B,D). Taken together, these experiments suggest that those epitopes recognized by mAbs 10 and 111 render cortical membranes more permissive for thalamic growth. In addition, the mAb 10 epitope is also involved in creating a less favorable environment for the growth of cortical axons.

To rule out the possibility that the antibodies exert their function by binding directly to growth cones, we repeated some experiments with pretreated membrane preparations. The membranes were first incubated with the respective antibody $(7 \mu \mathrm{g} / \mathrm{ml})$, excessive antibody was washed off, and they were then offered as substrate without the addition of more antibody to the culture medium. Under these conditions, results obtained with mAbs 111 and 10 (Fig. 5) were comparable to those described above. In fact, the effects were even more pronounced, as shown by a $72 \%$ reduction in growth for thalamic axons after pretreatment with mAb 10 and an almost threefold (278\%) enhancement for cortical axons. This indicates that the blocking of a growth-promoting epitope present in the membrane preparation-rather than a general impairment of growth cones-causes reduced outgrowth of thalamic fibers.

In the experiments described above, we analyzed axonal outgrowth by counting the number of distal ends of fibers extending from thalamic and cortical explants after 2-4 d in vitro. Because we found more cortical fiber endings in the presence of mAb 10 than under control conditions, one possible explanation of this result could be that mAb 10 induces branch formation and/or defasciculation of cortical axons but has no effect on axonal outgrowth per se. We therefore also measured the length of 



Figure 1. Immunofluorescence labeling with three different $\mathrm{mAbs}$ directed against rat postnatal cortical membrane preparations in the developing rat cortex. A, mab 10; B, mab 11; C, mab 942. Top, Frontal sections from P6 cortex; bottom, frontal sections from E19 cortex. To the left of each fluorescent image is a micrograph of the left half of the same section counterstained with bisbenzimide to illustrate the cortical layering. $M Z$, Marginal zone; $C P$, cortical plate; $S P$, subplate zone; $I Z$; intermediate zone; $V Z$, ventricular zone. Scale bars, $100 \mu \mathrm{m}$. 


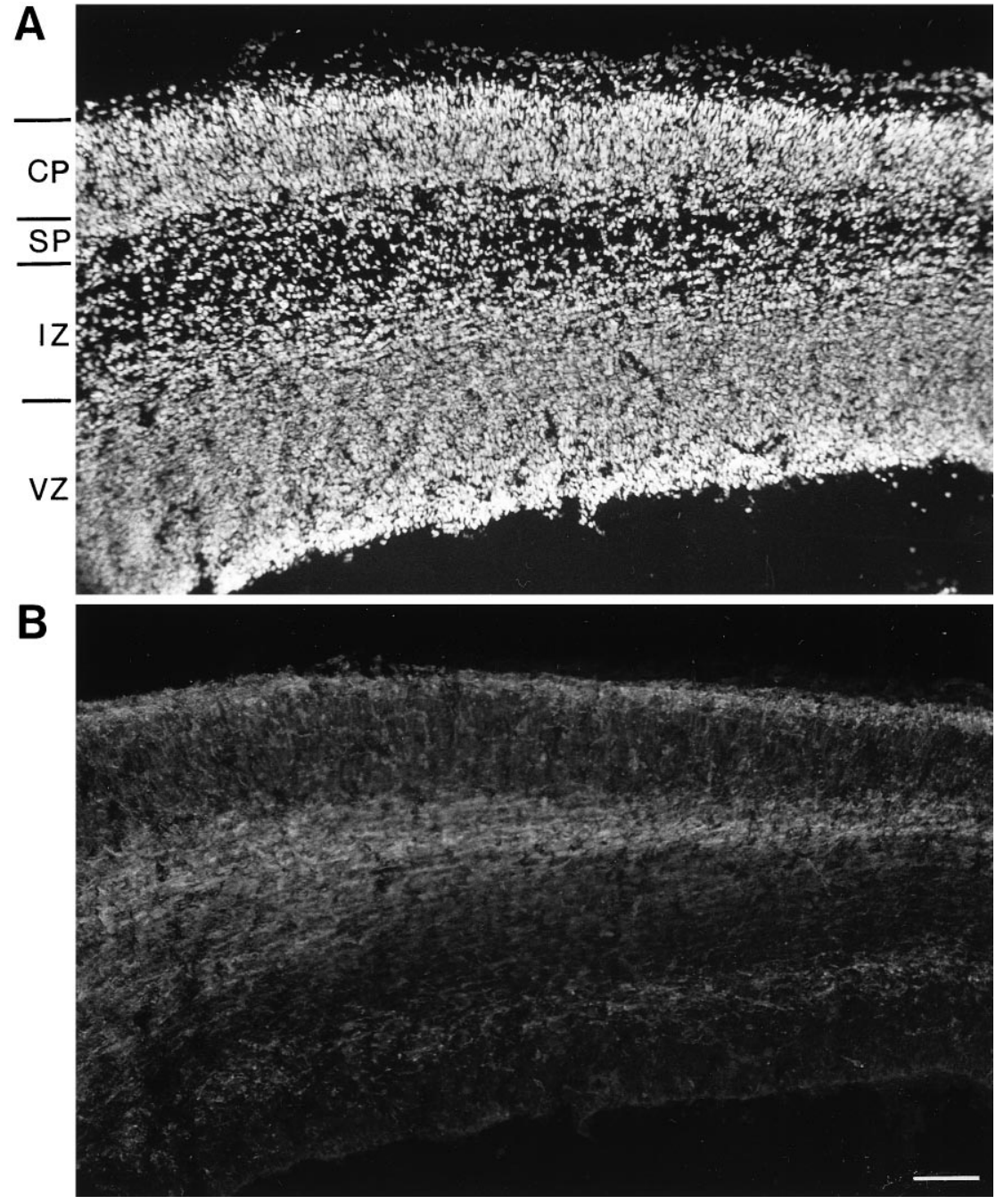

Figure 2. $\mathrm{mAb} 10$ labels the path of thalamocortical afferents and does not stain the corticofugal pathway. Double-labeling of a frontal section from E19 cortex; lateral is to the left, medial to the right. $A$, Bisbenzimide staining to reveal the cortical layering; $B$, immunohistochemical localization of $\mathrm{mAb} 10$ antigen. In the medial cortex, staining with mAb 10 is restricted to the $S P$. In the lateral cortex, mAb 10 labeling spreads into the upper part of the $I Z$, but the deep part of the IZ, the path of efferent cortical fibers, is not labeled. Same abbreviations as in Figure 1. Scale bar, $100 \mu \mathrm{m}$. cortical and thalamic axons extending on postnatal cortical membranes in the presence and absence of $\mathrm{mAb} 10$, and we used time-lapse video microscopy to study the influence of this antibody on the growth dynamic of axons. Figure 6 illustrates the distribution of the length of cortical and thalamic axons growing on cortical membranes after $2 \mathrm{~d}$ in vitro. The distribution for cortical axons on membranes preincubated with mAb 10, in comparison with the distribution on native membranes, was shifted to the right, i.e., toward larger axonal length (Fig. $5 B$ ). The $L_{50}$ value, the length exceeded by $50 \%$ of all axons (see Material and Methods), increased from $214.3 \mu \mathrm{m}$ on native membranes to $310.7 \mu \mathrm{m}$ on membranes treated with mAb 10 ( $p<0.0001 ; n=$ 655 axons). The opposite effect was observed with thalamic axons; here the curve was shifted to the left, i.e., toward shorter axonal length, after incubation of the membranes with mAb 10 (Fig. 5A). For thalamic axons, the $L_{50}$ value decreased from $464.3 \mu \mathrm{m}$ on native membranes to $314.3 \mu \mathrm{m}$ on membranes preincubated with mAb 10 ( $p<0.0001 ; n=308$ axons).

These results indicate that the epitope recognized by $\mathrm{mAb} 10$ influences the growth rate of cortical and thalamic axons in an opposing manner. To examine more closely the bifunctional action of this epitope, we used time-lapse imaging to study the growth behavior of cortical and thalamic axons growing on postnatal cortical membrane substrates with and without preincubation with $\mathrm{mAb} 10$. As reported previously for cortical fibers growing in vivo (Halloran and Kalil, 1994) and thalamic fibers growing in vitro (Hübener et al., 1995), axons did not grow at a constant speed but rather frequently changed their growth-rate, and sometimes the fibers even stopped growing and then started to grow again. Such stops either were accompanied by growth cone collapse and fiber retraction or the axons stopped elongating without growth cone collapse. In these cases, the growth cones continued to extend and retract their filopodia, but there was no net forward movement of the growth cones. Cortical axons extending on native postnatal cortical membranes halted their growth 1.3 times per hour, and the average pause duration was $14.2 \mathrm{~min}$ (Table 1). The mean growth rate was $33.1 \mu \mathrm{m} / \mathrm{hr}$; the net speed, the rate of extension during the growth phase, was 46.7 $\mu \mathrm{m} / \mathrm{hr}$. On average, cortical axons reached a maximal growth rate of $101.3 \mu \mathrm{m} / \mathrm{hr}$ (Table 1). There was no statistical significant difference between cortical and thalamic axons in any of the five parameters analyzed (Table 1).

After preincubation of cortical membranes with mAb 10, the mean growth rate, as well as the net and maximal growth speed of cortical axons, was increased significantly compared with untreated membranes. The addition of mAb 10 to the membranes had no effect on the number of pauses, but the pause duration decreased by $33 \%$ (Table 1). Figure 7 depicts representative reconstructions from time-lapse recordings of trajectories of representative cortical axons growing on a membrane substrate in the 

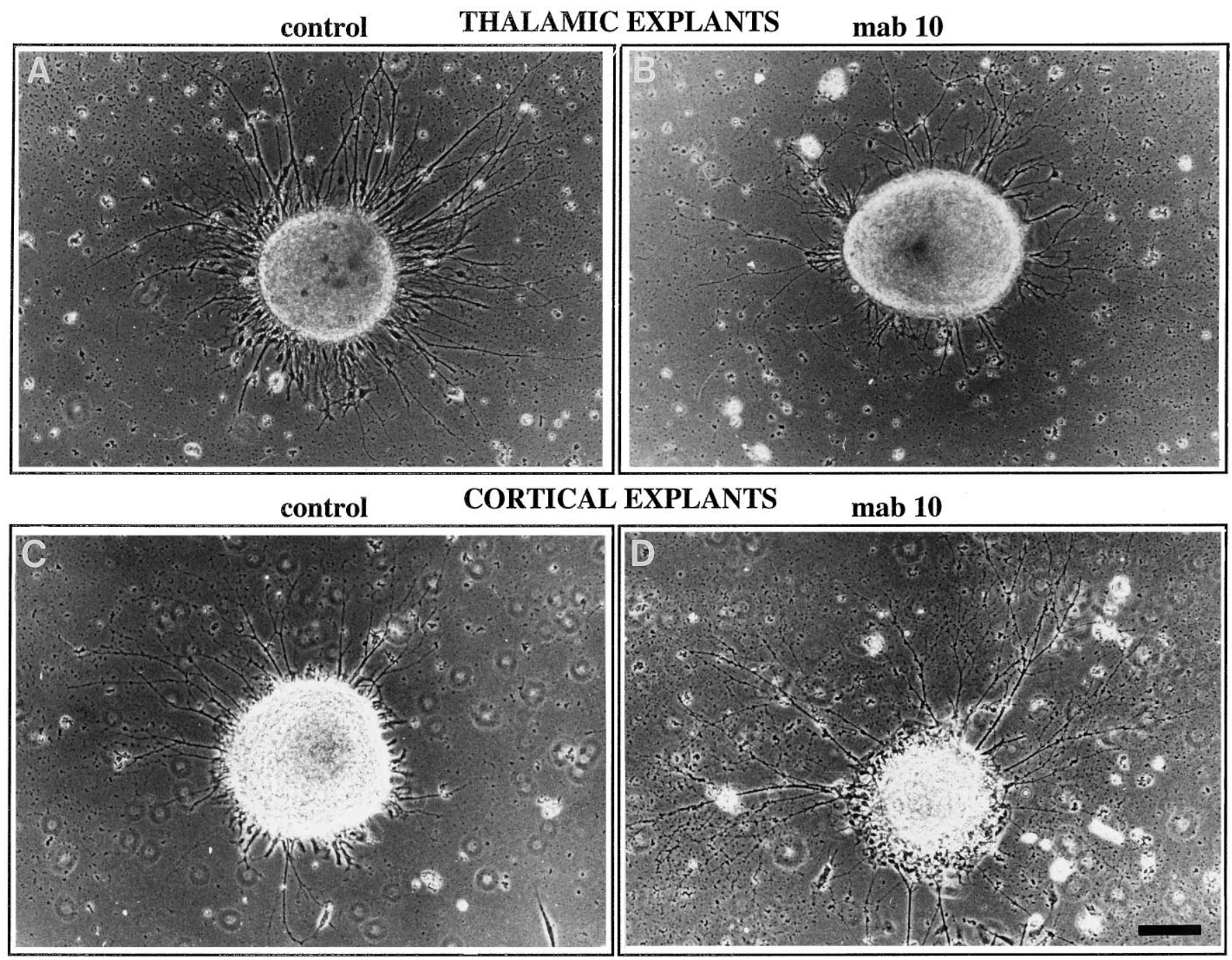

Figure 3. Effect of mAb 10 on axonal outgrowth. Phase-contrast micrographs of E16 $(A, B)$ thalamic and $(C, D)$ cortical explants on postnatal cortical membranes after $4 \mathrm{~d}$ in vitro. $A, C$, Outgrowth under control conditions and $(B, D)$ after addition of mAb $10($ mab 10$)$. mAb 10 reduces the extension of thalamic axons, whereas outgrowth of cortical axons is enhanced. Scale bar (shown in $D$ ): $100 \mu \mathrm{m}$.

presence and absence of mAb 10. For thalamic axons, each of the three parameters related to growth speed decreased significantly by $>30 \%$ after incubation of the cortical membranes with mAb 10; however, mAb 10 had no influence on the number and duration of the growth pauses of thalamic axons (Table 1).

\section{Biochemical characterization of the antigens recognized by mAbs 10, 111, and 942}

As an initial attempt to analyze the antigens that the antibodies (described above) recognize in cortex, immunoblotting was performed with material from embryonic and postnatal rat cortex. We first determined the solubilization properties of the antigens by extracting the tissue under various conditions $(20 \mathrm{~mm}$ Tris- $\mathrm{HCl}$, $2 \mathrm{M} \mathrm{NaCl}$, and $6 \mathrm{M}$ urea or $0.1 \%$ Chaps) and monitoring the extraction in dot blots. Among these, only $6 \mathrm{~m}$ urea proved to be effective, suggesting that the molecules might be constituents of the extracellular matrix. Urea extracts were then applied to $10 \%$ SDS-PAGE gels and run under reducing conditions. After electrophoretic transfer, no signal was found with $\mathrm{mAb} 942$, whereas mAbs 10 and 111 both stained a broad band of similar molecular weight. Because some ECM molecules such as proteoglycans have very high molecular weights that hinder them from entering the gel matrix, enzyme digestions were performed after dialysis of urea-extracted material and then analyzed after separation in $7 \%$ and $10 \%$ SDS-PAGE and subsequent transfer onto nitrocellulose. Results for mAb 10 are shown in Figure 8. A broad smear extending from 180 to $370 \mathrm{kDa}$ is visible after separating proteins in a $7 \%$ gel (Fig. $8 A$ ), unaltered by digestion with chondroitinase $\mathrm{ABC}$, chondroitinase $\mathrm{AC}$, keratinase, and heparitinase, respectively. This result proves that the antigen is not a proteoglycan. Molecular weights extending over broad ranges are also found for glycoproteins; therefore, the experiment was repeated and included a digestion with the glycosidase PNGase F (peptide: $N$-glycosidase F; Fig. $8 B$ ). Under these conditions, the signal is abolished completely, indicating that the epitope recognized by $\mathrm{mAb} 10$ is a carbohydrate epitope.

To verify that this carbohydrate epitope is associated exclusively with the high molecular weight glycoprotein present in the urea extract, cortical tissue was homogenized, and the resulting sediment after centrifugation was solubilized in the sample buffer. After separation in $10 \%$ SDS-PAGE and electrophoretic transfer, 


\section{thalamic axons}

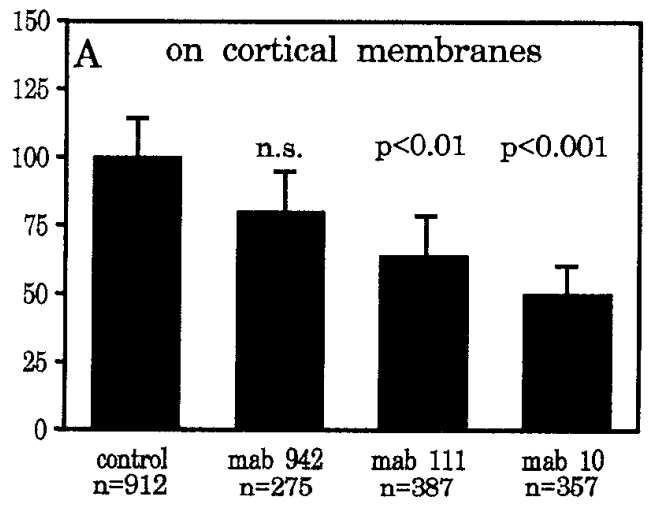

cortical
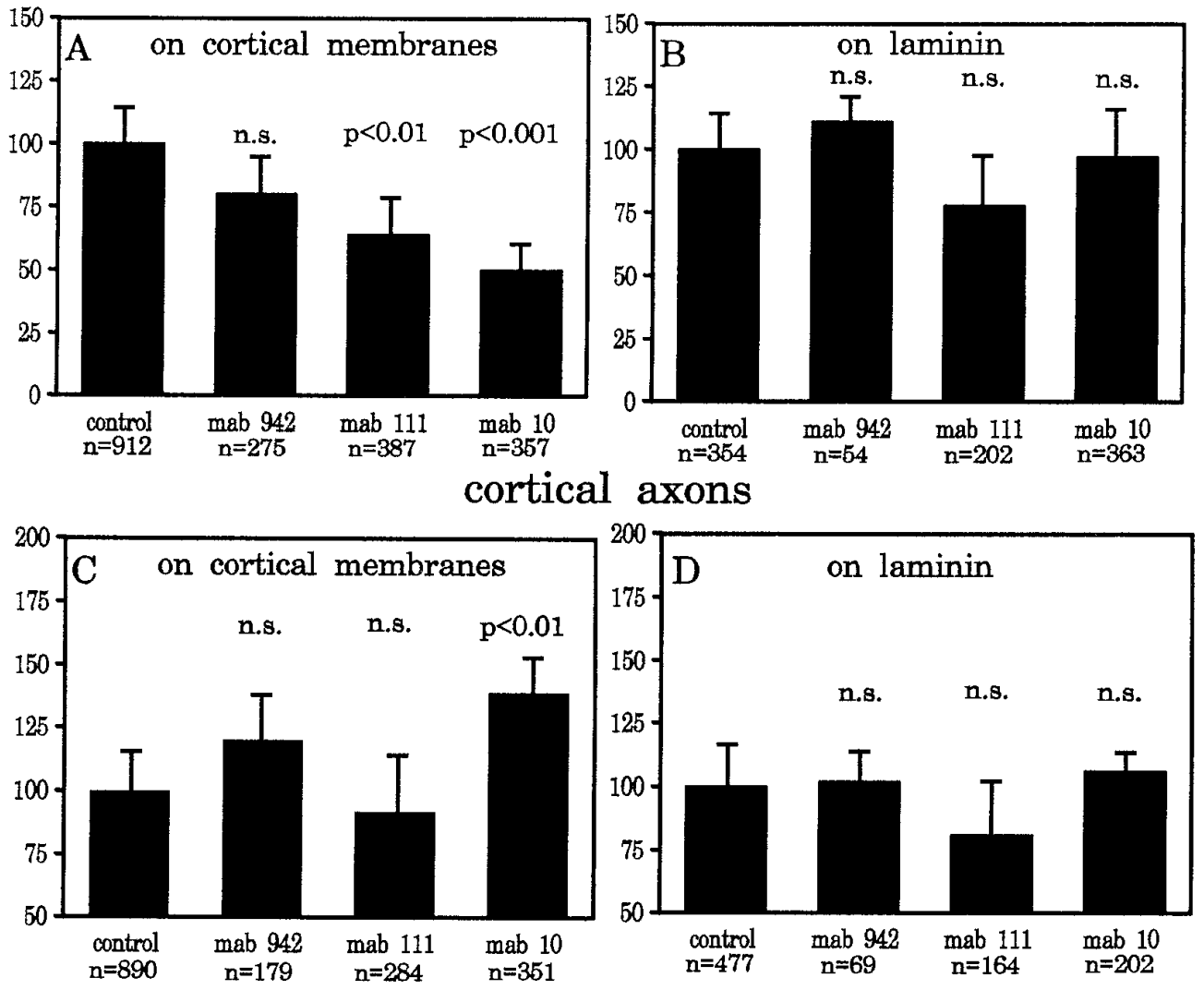

Figure 4. Histograms of axonal outgrowth from E16 thalamic and cortical explants after the addition of mAbs to the medium. The vertical axes depict the average number of outgrowing fibers per explant relative to the outgrowth of explants in the absence of the antibodies (control). A, Outgrowth of thalamic axons on cortical membranes is reduced significantly in the presence of mAbs 111 and 10 , whereas $\mathrm{mAb} 942$ exerts no significant effect (n.s.). B, Outgrowth of thalamic fibers is not influenced by these antibodies on a laminin substrate. $C$, Cortical axons growing on cortical membranes respond with enhanced outgrowth to the presence of $\mathrm{mAb} 10$, indicating that the antibody blocks an epitope inhibitory for these fibers. $D$, Outgrowth of cortical axons on laminin is not altered significantly by any of the antibodies. Error bars indicate the SEM; $n=$ number of explants. incubation with mAb 10 revealed a band of the same molecular weight as in the urea extracts (Fig. $8 B$, lane 7). Because no reactivity was found in either the soluble supernatant or with detergent extracts, we conclude that the $180-370 \mathrm{kDa}$ glycoprotein is the only cortical protein associated with the mAb 10 epitope.

For $\mathrm{mAb} 942$, incubation with chondroitinase $\mathrm{ABC}$ generates a core protein of $68 \mathrm{kDa}$; all other treatments (enzymes as above) do not result in changes as compared with the control (data not shown). Faint staining is visible at the application site of the stacking gel, which becomes a clear signal when a second filter is applied during the electrophoretic transfer. Thus the 942 antigen seems to be a high molecular weight chondroitin sulfate proteo- glycan with a core protein of apparent molecular weight $68 \mathrm{kDa}$. The molecular weight of the undigested proteoglycan is not yet known.

\section{DISCUSSION}

Glycosylated molecules previously have been suggested to be involved in regulating cortical invasion by thalamic axons (Götz et al., 1992; Bolz et al., 1993; Tuttle et al., 1995). To identify such molecules, we raised mAbs against membrane preparations from postnatal cortex and tested their ability to interfere with axonal growth from thalamic and cortical explants on a membrane substrate. One antibody (mAb 10) recognizing a carbohydrate epitope of a membrane-associated glycoprotein had opposite ef-

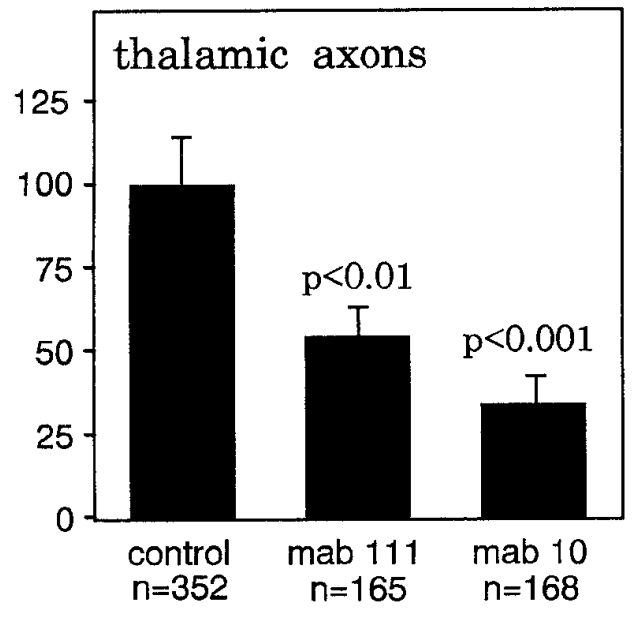

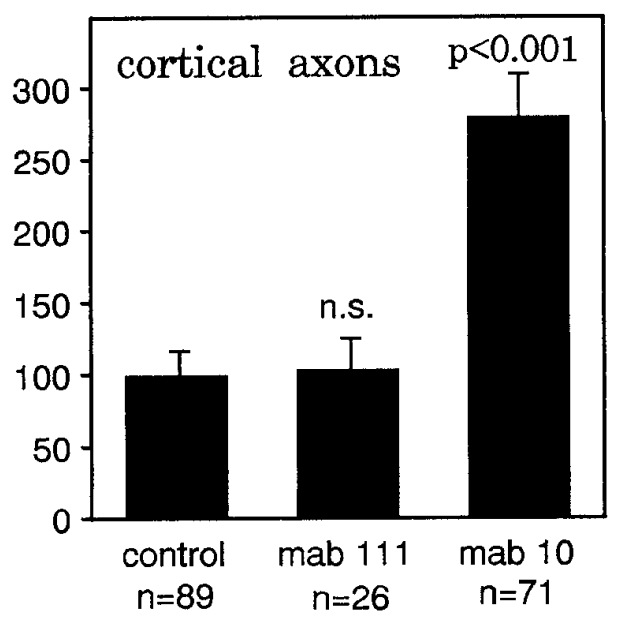

Figure 5. Histograms of axonal outgrowth from explants prepared at E16 on cortical membranes preincubated with $\mathrm{mAbs}$ as indicated. The vertical axes depict the average number of fibers per explant relative to control explants; the SEM and statistical significance are indicated at the top of each column; $n=$ number of explants. 

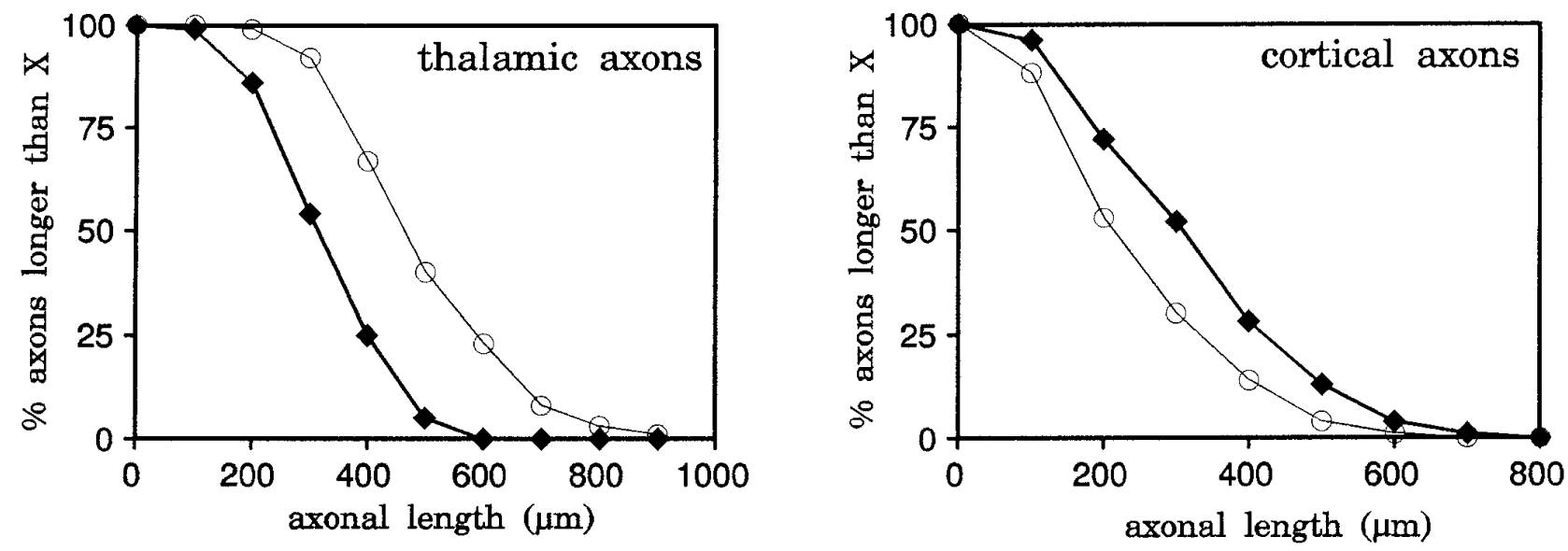

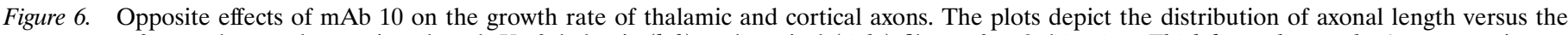

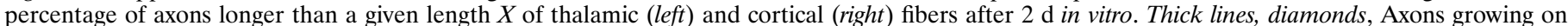
cortical membranes preincubated with mAb 10; thin lines, circles, axons extending on native membranes.

fects on afferent and efferent fibers: it reduced the growth rate of thalamic axons, whereas it enhanced the growth speed of cortical axons. In addition, cortical axons stopped their growth for shorter periods of time on cortical membranes preincubated with mAb 10 compared with untreated membranes. As discussed below, this dual action of mAb 10 might explain the segregation of afferent and efferent cortical pathways. Moreover, the spatiotemporal distribution of the carbohydrate epitope defined by mAb 10 , together with its action on growing thalamic axons, suggests that it might play an important role in regulating the timing of thalamocortical innervation.

\section{Molecular heterogeneity of axonal pathways in developing cortex}

The three antibodies that were characterized in the present study were selected because the developmental expression pattern of their respective antigens correlated with the time course of cortical innervation by thalamic axons. Immunohistological investigations using antibodies directed against other constituents of the extracellular matrix also revealed an expression of the respective antigens regulated spatially and temporally in developing cortex (Stewart and Perlman, 1987; Chun and Shatz, 1988; Sheppard et al., 1991; Bignami et al., 1992; Hunter et al., 1992; Bicknese et al., 1994; Oohira et al., 1994). Among these, laminin and fibronectin, which have been described as supporting the extension of neurites especially from the peripheral nervous system but also from various central neurons (Sanes, 1985), are present at early stages of cortical development. Expression is highest in the subplate (Chun and Shatz, 1988; Hunter et al., 1992), where the path of thalamic fibers is centered during the phase of intracortical growth toward their target area. The level of expression, however, declines with ongoing development, and no substantial amounts of either laminin or fibronectin are detectable in the cortical plate and the cortical layers generated at later stages (Stewart and Perlman, 1987; Chun and Shatz, 1988; Sheppard et al., 1991). Although this distribution might suggest an involvement of these molecules in early ingrowth of thalamic afferents, the lack of expression in the ultimate cortical layers also supports the interpretation that they most likely do not contribute to the lateroccurring cortical invasion by thalamic axons.

A closer spatial and temporal correlation with cortical innervation could be demonstrated for the expression pattern of chondroitin sulfate proteoglycans (Bicknese et al., 1994; Miller et al., 1995). The growth of thalamocortical afferents into the cortical plate coincides with a progressive increase of CSPGs from deep to superficial cortical plate. Other molecules that increase in the cortical plate during thalamocortical afferent invasion include the ECM glycoprotein tenascin (cytotactin) and the membraneassociated cell adhesion molecules L1 and TAG-1 (Fushiki and Schachner, 1986; Chung et al., 1991; Sheppard et al., 1991; Wolfer et al., 1994; Tuttle et al., 1995). Although the immunohistological and cytochemical studies reveal a complex molecular heterogeneity of developing cortex and suggest a role of these molecules in promoting cortical invasion by thalamic axons, this has yet to be demonstrated directly in most cases. Furthermore, our results and those of others (Faissner and Kruse, 1990; Wehrle and Chiquet, 1990; Colamarino and Tessier-Lavigne, 1995) indicate that axonal subpopulations respond differentially to individual molecules or molecular domains, and the expression patterns as such do not necessarily allow prediction of the influence that these molecules exert on different axons.

Table 1. Effect of mAb 10 on the growth of cortical and thalamic axons

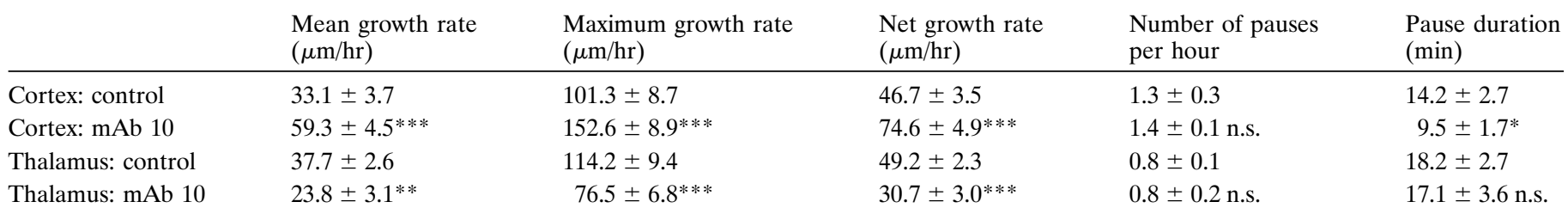

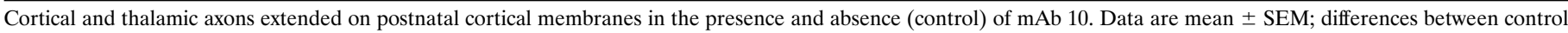
and mAb 10 incubated membranes. n.s., Not significant; ${ }^{*} p<0.05 ;{ }^{* *} p<0.01$; ${ }^{* * *} p<0.001$. 

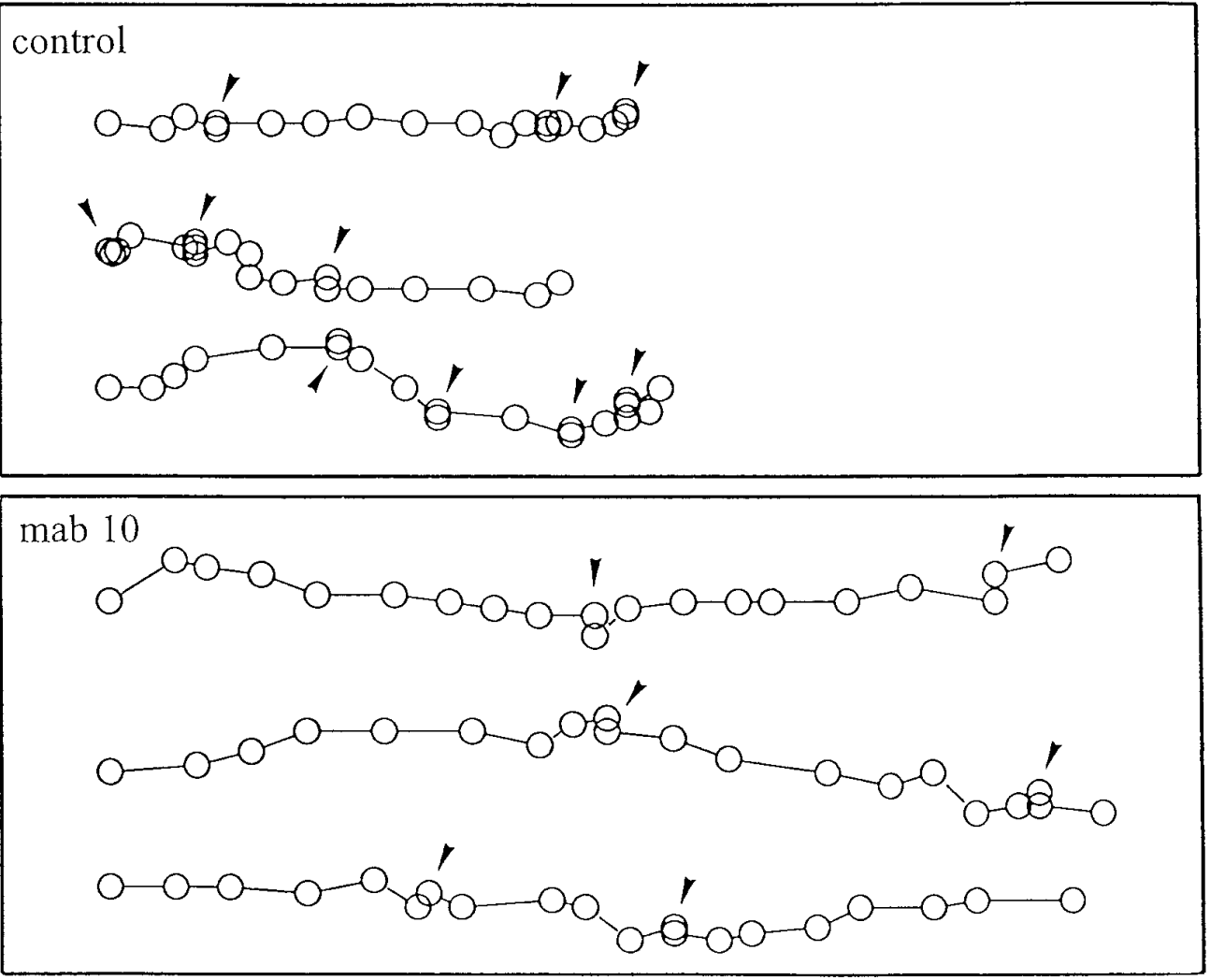

Figure 7. Reconstructions of axonal trajectories from time-lapse imaging, each recorded for $100 \mathrm{~min}$, of cortical fibers growing on native cortical membranes (top) and on membranes preincubated with mAb 10 (bottom). The positions of the growth cones are plotted every $5 \mathrm{~min}$; the site of the circles corresponds approximately to the size of a growth cone. Arrows point to growth pauses. Incubation of cortical membranes with $\mathrm{mAb} 10$, compared with untreated membranes, increased the growth speed and decreased the pause duration of cortical axons. Scale bar, $30 \mu \mathrm{m}$.

\section{Involvement of carbohydrate epitopes in pathfinding and targeting of axons}

Our experiments performed with $\mathrm{mAb} 10$ demonstrate that a glycoprotein-associated carbohydrate epitope can perform a dual function in axonal growth. Although this epitope influences extension of thalamic axons in a positive fashion, it decreases the growth speed of cortical axons. Carbohydrates on the neural surface or in the matrix are being associated with many developmental events involving the regulation of cell adhesion or recognition. Highly acidic carbohydrates seem to contribute to axonal branching and guidance (Landmesser et al., 1990; Wang and Denburg, 1992; Grumet et al., 1993). In some cases, their differential distribution underlies selective reinnervation during regeneration (Martini et al., 1992). Neutral carbohydrates have been implicated in neuronal migration and axonal growth (Lehmann et al., 1990) as well as pathfinding and targeting (Dodd and Jessell, 1986; Schwarting et al., 1992; Song and Zipser, 1995). Although the biochemical analysis of the carbohydrates involved in influencing the growth of thalamic and cortical axons as described in the present study does not allow assignment of the activity to a single identified carbohydrate, the cleavage characteristics of the enzyme used (PNGase F) suggest that the epitope specifically recognized by $\mathrm{mAb} 10$ belongs to the group of N-linked carbohydrates of either the complex or high mannose type. In addition, these results also propose that other carbohydrate structures are adding to the preferred growth of thalamic fibers on postnatal membranes. Previous investigations showed that incubation with peanut agglutinin reduces the growth-supporting properties of the membranes (Götz et al., 1992). Because this lectin binds to a core structure [Gal-( $\beta 1-3)-G a l N A c]$ present in O-linked carbohydrates that are common to many membrane glycoproteins, it seems unlikely that $\mathrm{mAb} 10$ and peanut agglutinin recognize the same epitope. Thus, several different protein domains as well as carbohydrate epitopes might contribute to the observed phenomenon, which is also evidenced by the fact that neither of the reagents completely abolishes outgrowth of thalamic axons.

\section{Do growth-promoting molecules define thalamocortical pathways?}

Initial intracortical growth of thalamic fibers is confined to the subplate and the upper intermediate zone. Short collateral branches extend upward toward the cortical plate and reach into the lower cortical plate in more mature areas of the cortical wall (De Carlos and O'Leary, 1992; Bicknese et al., 1994); however, axons grow into the cortex only when the definite layers are formed. So far, the mechanisms that restrict the path of thalamic axons have remained elusive. In various parts of the nervous system, inhibitory or repulsive factors that contribute to axonal pathfinding have been described (Kapfhammer and Raper, 1987; Walter et al., 1987a; Davies et al., 1990; Moorman and Hume, 1990; Pini, 1993). Many molecules that inhibit axonal growth cause a collapse of the growth cone and thereby restrict axonal elongation to specific pathways (Cox et al., 1990; Luo et al., 1993). Although such mechanisms might also operate in the immature cortex, to date most investigations have not provided evidence for inhibitory factors guiding thalamic fibers into cortex (Hübener et al., 1995; Tuttle et al., 1995). Evidence presented so far indicated that growth-promoting molecules define the pathway for thalamocortical afferents, although it must be noted that the data were obtained in vitro and molecules might be lost or masked by the preparation procedure. Our current results obtained with mAbs 10 and 111 support the previous findings. Both antibodies interact 


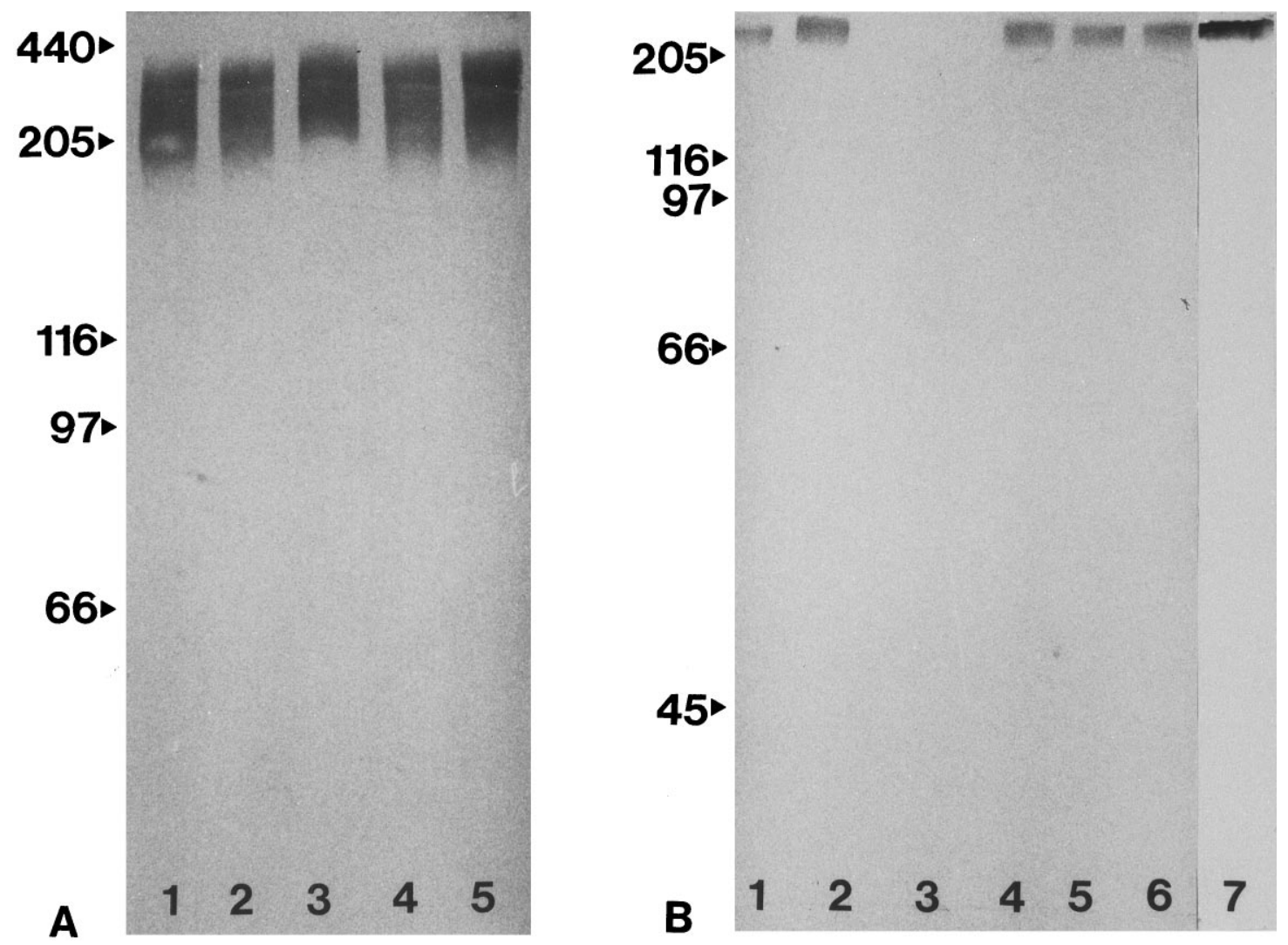

Figure 8. Biochemical characterization of the mAb 10 antigen. Western blots of $6 \mathrm{~m}$ urea extracts obtained from P6 cortex, dialyzed, and incubated with enzymes as indicated. $A$, Separation of proteins by a $7 \%$ SDS-PAGE gel under reducing conditions. Samples were digested with (1) keratinase, (2) heparitinase, (3) chondroitinase AC, or (4) chondroitinase ABC, or (5) incubated without enzyme. B, Separation of proteins by a $10 \%$ SDS-PAGE gel under reducing conditions after incubation with (1) keratinase, (2) heparitinase, (3) $N$-glycosidase F, (4) chondroitinase ABC, or (5) chondroitinase AC, (6) without enzyme, and (7) cortical tissue solubilized directly in sample buffer. mAb 10 binds to a carbohydrate epitope of a 180-370 kDa glycoprotein. Molecular weight of marker proteins in kilodaltons.

with growth-supporting components present in the membrane preparation without directly influencing the growth cone, as evidenced by experiments using the EHS tumor-derived laminin as substrate or by preincubating membranes with antibodies before attachment to coverslips. The enrichment of these components in the subplate and later in the developing intermediate zone, possibly together with already described or as yet unidentified molecules, might explain the growth of axons along this rather narrow sheet of cells.

\section{Regulation of cortical invasion: a molecular basis for waiting periods}

A time delay between the arrival of thalamic fibers in the cortex and invasion into the developing cortical layers has been described in several species. Afferent fibers reach the cortex before most cortical neurons have been born or layers have been formed. It has been suggested that the lack of sufficiently high levels of growth-promoting molecules in the undifferentiated cortical plate might hinder the afferents from invading a tissue that still lacks the target neurons (Götz et al., 1992; Bolz et al., 1993; Tuttle et al., 1995). Our observations on expression of several epitopes recognized by mAbs 10,111, and 942 support the notion that such molecules are missing in the embryonic cortex. They do not necessarily need to act by providing a growth-permissive function themselves, but instead might contribute to create a favorable environment by binding and subsequently presenting growth factors to cells and growth cones, as has been demonstrated for various proteoglycans (Andres et al., 1989; Yayon et al., 1991). By acting in concert, these molecules could provide the molecular basis for cortical invasion.

\section{A dual mechanism for segregation of cortical inputs and outputs}

Thalamic afferents follow a pathway that is different from the path taken by efferent fibers. The trajectories of the two axonal populations are separated within the white matter (Woodward et al., 1990), and this segregation is already apparent at early developmental stages (De Carlos and O'Leary, 1992; Miller et al., 1993). Among the mechanisms that underlie the segregation of afferent and efferent axons, fiber-fiber interactions and specific interactions with growth-permitting or inhibiting molecules might play an important role (Blakemore and Molnar, 1991; De Carlos and O'Leary, 1992; Miller et al., 1995). A selective fasciculation of cortical axons with other cortical axons has been described in vitro (Bagnard et al., 1995; Bolz et al., 1995). In addition, cortical fibers tend to avoid thalamic fibers. Although these findings could explain the segregation into different fiber tracts, they do not explain the preference for a certain localization within the developing white matter. Our results obtained with mAb 10 might contribute to an understanding of how these positions are selected. The first axons arising from subplate neurons leave the cortex before thalamic fibers have arrived. The later descending cortical plate neurons probably use axons from the subplate as pioneer fibers (McConnell et al., 1989, 1994); however, they take 
an even deeper position in the intermediate zone than those axons and grow below but possibly along them (McConnell et al., 1989; Ghosh and Shatz, 1992; Bicknese et al., 1994), thus indicating that they either avoid an unfavorable molecular environment in the upper intermediate zone or are attracted by molecules expressed just above the ventricular zone. The differential distribution of the $\mathrm{mAb} 10$ epitope in the intermediate zone, together with its function in decreasing outgrowth of cortical axons-as evidenced by the increased growth rate after masking this epitope by antibody incubation-makes it a good candidate for a molecule that is avoided by cortical axons, thus causing them to grow in the deep intermediate zone where only small amounts of the epitope are present. At the same time, the same molecule might attract afferent fibers into areas expressing a higher level of this epitope. Whether this behavior depends on different sets of receptors expressed by efferent and afferent cortical fibers or on the same receptors connected to different signaling pathways remains unclear. A combination of fiber-fiber interactions and the unequal distribution of substrate-bound molecules interpreted in opposing ways by different fiber populations might thus underlie the observed segregation and localization of axons in the white matter.

\section{REFERENCES}

Andres JL, Stanley K, Cheifetz S, Massague J (1989) Membraneanchored and soluble forms of betaglycan, a polymorphic proteoglycan that binds transforming growth factor- $\beta$. J Biol Chem 109:3137-3145.

Bagnard D, Mann F, Henke-Fahle S, Bolz J (1995) Developmental mechanisms underlying the segregation of afferent and efferent cortical projections. Soc Neurosci Abstr 21:1285.

Baier H, Bonhoeffer F (1992) Axon guidance by gradients of a targetderived component. Science 255:472-475.

Bicknese AR, Sheppard AM, O'Leary DDM, Pearlman AL (1994) Thalamocortical axons extend along a chondroitin sulfate proteoglycanenriched pathway coincident with the neocortical subplate and distinct from the efferent path. J Neurosci 14:3500-3510.

Bignami A, Asher R, Perides G (1992) Co-localization of hyaluronic acid and chondroitin sulfate proteoglycan in rat cerebral cortex. Brain Res 579:173-177.

Bixby JL, Harris WA (1991) Molecular mechanisms of axon growth and guidance. Annu Rev Cell Biol 7:117-159.

Blakemore C, Molnar Z (1991) Lack of regional specificity for connections formed between thalamus and cortex in coculture. Nature 351:475-477.

Bolz J, Götz M, Hübener M, Novak N (1993) Reconstructing cortical connections in a dish. Trends Neurosci 16:310-316.

Bolz J, Kossel A, Bagnard D (1995) The specificity of interconnections between thalamus and cortex. In: Development of the cerebral cortex. Ciba Foundation Symposium 193 (Bock G, Cardew G, eds), pp 173191. New York: Wiley.

Bradford M (1976) A rapid and sensitive method for the quantitation of microgram quantities of protein utilizing the principle of protein-dye binding. Anal Biochem 72:248-254.

Catalano SM, Robertson RT, Killackey HP (1991) Early ingrowth of thalamocortical afferents to the neocortex of the prenatal rat. Proc Natl Acad Sci USA 88:2999-3003.

Chang S, Rathjen FG, Raper JA (1987) Extension of neurites on axons is impaired by antibodies against specific neural cell surface glycoproteins. J Cell Biol 104:355-362.

Chun JJM, Shatz CJ (1988) A fibronectin-like molecule is present in the developing cat cerebral cortex and is correlated with subplate neurons. J Cell Biol 106:857-872.

Chung W-W, Lagenaur CF, Yan Y, Lund JS (1991) Developmental expression of neural cell adhesion molecules in the mouse neocortex and olfactory bulb. J Comp Neurol 314:290-305.

Colamarino S, Tessier-Lavigne M (1995) The axonal chemoattractant netrin-1 is also a chemorepellent for trochlear motor axons. Cell 81:621-629.

Cox EC, Müller B, Bonhoeffer F (1990) Axonal guidance in the chick visual system: posterior tectal membranes induce collapse of growth cones from the temporal retina. Neuron 4:31-37.
Davies JA, Cook GMW, Stern CD, Keynes RJ (1990) Isolation from chick somites of a glycoprotein that causes collapse of dorsal root ganglion growth cones. Neuron 4:11-20.

De Carlos JA, O'Leary DDM (1992) Growth and targeting of subplate axons and establishment of major cortical pathways. J Neurosci 12:1194-1211.

De Curtis I, Quaranta V, Tamura RN, Reichardt LF (1991) Laminin receptors in the retina: sequence analysis of the chick integrin a6 subunit: evidence for transcriptional and posttranslational regulation. $\mathbf{J}$ Cell Biol 113:405-416.

Dodd J, Jessell TM (1986) Cell surface glycoconjugates and carbohydrate-binding proteins: possible recognition signals in sensory neuron development. J Exp Biol 124:225-238.

Dodd J, Morton SB, Karagogeos D, Yamamoto M, Jessell TM (1988) Spatial regulation of axonal glycoprotein expression on subsets of embryonic spinal neurons. Neuron 1:105-116.

Faissner A, Kruse J (1990) J1/Tenascin is a repulsive substrate for central nervous system neurons. Neuron 5:627-637.

Fazekas de St.Groth S, Scheidegger D (1980) Production of monoclonal antibodies: strategies and tactics. J Immunol Methods 35:1-21.

Fushiki S, Schachner M (1986) Immunocytological localization of cell adhesion molecules L1 and N-CAM and the shared carbohydrate epitope L2 during development of the mouse neocortex. Dev Brain Res 24:153-167.

Ghosh A, Shatz CJ (1992) Pathfinding and target selection by developing geniculocortical axons. J Neurosci 12:39-55.

Goodman CS, Shatz CJ (1993) Developmental mechanisms that generate precise patterns of neuronal connectivity. Neuron 10:77-98.

Götz M, Novak N, Bastmeyer M, Bolz J (1992) Membrane bound molecules in rat cerebral cortex regulate thalamic innervation. Development 116:507-519.

Grumet M, Flaccus A, Margolis RU (1993) Functional characterization of chondroitin sulfate proteoglycans of brains: interactions with neurons and neural cell adhesion molecules. J Cell Biol 120:815-824.

Halloran MC, Kalil K (1994) Dynamic behaviors of growth cones extending in the corpus callosum of living cortical brain slices observed with video microscopy. J Neurosci 14:2161-2177.

Henke-Fahle S, Götz M, Wild K, Bolz J (1994) Monoclonal antibodies define growth-promoting molecules specific for thalamic axons. Soc Neurosci Abstr 20:216.

Hübener M, Götz M, Klostermann S, Bolz J (1995) Guidance of thalamocortical axons by growth-promoting molecules in developing rat cerebral cortex. Eur J Neurosci 7:1963-1972.

Hunter DD, Llinas R, Ard M, Merlie JP, Sanes JR (1992) Expression of s-laminin in the developing rat central nervous system. J Comp Neurol 323:238-251.

Kageyama GH, Robertson RT (1993) Development of geniculocortical projections to visual cortex in rat: evidence for early ingrowth and synaptogenesis. J Comp Neurol 335:123-148.

Kapfhammer JP, Raper JA (1987) Collapse of growth cone structure on contact with specific neurites in culture. J Neurosci 7:201-212.

Kostovic I, Rakic P (1990) Developmental history of the transient subplate zone in the visual and somatosensory cortex of the macaque monkey and human brain. J Comp Neurol 297:441-470.

Lander AD (1993) Proteoglycans in the nervous system. Curr Opin Neurobiol 3:716-723.

Landmesser L, Dahm L, Tang J, Rutishauser U (1990) Polysialic acid as a regulator of intramuscular nerve branching during embryonic development. Neuron 4:655-667.

Lehmann S, Kuchler S, Theveniau M, Vincendon G, Zanetta J-P (1990) An endogenous lectin and one of its neuronal glycoprotein ligands are involved in contact guidance of neuron migration. Proc Natl Acad Sci USA 87:6455-6459.

Lin C-H, Thompson CA, Forscher P (1994) Cytoskeletal reorganization underlying growth cone motility. Curr Opin Neurobiol 4:640-647.

Lochter A, Schachner M (1993) Tenascin and extracellular matrix proteins: from promotion to polarization of neurite growth in vitro. J Neurosci 13:3986-4000.

Lund RD, Mustari MJ (1977) Development of the geniculocortical pathway in rats. J Comp Neurol 173:289-306.

Luo Y, Raible D, Raper JA (1993) Collapsin: a protein in brain that induces the collapse and paralysis of neuronal growth cones. Cell 75:217-227. 
Martini R, Xin Y, Schmitz B, Schachner M (1992) The L2/HNK-1 carbohydrate epitope is involved in the preferential outgrowth of motor neurons on ventral roots and motor nerves. Eur J Neurosci 4:628-639.

McConnell SK, Ghosh A, Shatz CJ (1989) Subplate neurons pioneer the first axon pathway from the cerebral cortex. Science 245:978-982.

McConnell SK, Ghosh A, Shatz CJ (1994) Subplate pioneers and the formation of descending connections from cerebral cortex. J Neurosci 14:1892-1907.

Miller B, Chou L, Finlay BL (1993) The early development of thalamocortical and corticothalamic projections. J Comp Neurol 335:16-41.

Miller B, Sheppard AM, Bicknese AR, Pearlman AL (1995) Chondroitin sulfate proteoglycans in the developing cerebral cortex: the distribution of neurocan distinguishes forming afferent and efferent axonal pathways. J Comp Neurol 355:615-628.

Moorman SJ, Hume RI (1990) Growth cones of chick sympathetic preganglionic neurons in vitro interact with other neurons in a cellspecific manner. J Neurosci 10:3158-3163.

Oohira A, Matsui F, Watanabe E, Kushima Y, Maeda N (1994) Developmentally regulated expression of a brain specific species of chondroitin sulfate proteoglycan, neurocan, identified with a monoclonal antibody IG2 in the rat cerebrum. Neuroscience 60:145-157.

Pini A (1993) Chemorepulsion of axons in the developing mammalian central nervous system. Science 261:95-98.

Rakic P (1977) Prenatal development of the visual system in rhesus monkey. Philos Trans R Soc Lond [Biol] 278:245-260.

Sanes JR (1985) Laminin for axonal guidance? Nature 315:714-715.

Schwarting GA, Deutsch G, Gattey DM, Crandall JE (1992) Glycoconjugates are stage- and position-specific molecules in the developing olfactory system. II. Unique carbohydrate antigens are topographic markers for selective projection patterns of olfactory axons. J Neurobiol 23:130-142.

Shatz CJ, Luskin MB (1986) The relationship between the geniculocortical afferents and their cortical target cells during development of the cat's primary visual cortex. J Neurosci 6:3655-3668.
Sheppard AM, Hamilton SK, Perlman AL (1991) Changes in the distribution of extracellular matrix components accompany early morphogenetic events of mammalian cortical development. J Neurosci 11:3928-3942.

Song J, Zipser B (1995) Targeting of neuronal subsets mediated by their sequentially expressed carbohydrate markers. Neuron 14:537-547.

Stewart GR, Perlman AL (1987) Fibronectin-like immunoreactivity in the developing cerebral cortex. J Neurosci 7:3325-3333.

Tuttle R, Schlaggar BL, Braisted JE, O'Leary DDM (1995) Maturationdependent upregulation of growth-promoting molecules in developing cortical plate controls thalamic and cortical neurite growth. J Neurosci 15:3039-3052.

Walter J, Henke-Fahle S, Bonhoeffer F (1987a) Avoidance of posterior tectal membranes by temporal axons. Development 101:909-913.

Walter J, Kern-Veits B, Huf J, Stolze B, Bonhoeffer F (1987b) Recognition of position-specific properties of tectal cell membranes by retinal axons in vitro. Development 101:685-696.

Wang L, Denburg JL (1992) A role for proteoglycans in the guidance of a subset of pioneer axons in cultured embryos of the cockroach. Neuron 8:701-714.

Wehrle B, Chiquet M (1990) Tenascin is accumulated along developing peripheral nerves and allows neurite outgrowth in vitro. Development 110:401-415.

Wolfer DP, Henehan-Beatty A, Stoeckli ET, Sonderegger P, Lipp H-P (1994) Distribution of TAG-1/axonin-1 in fibre tracts and migratory streams of the developing mouse nervous system. J Comp Neurol 345:1-32.

Woodward WA, Chiaia N, Teyler TJ, Leong L, Coull BM (1990) Organization of cortical afferent and efferent pathways in the white matter of the rat visual system. Neuroscience 36:393-401.

Yayon A, Klagsbrun M, Esko JD, Leder P, Ornitz DM (1991) Cell surface heparin-like molecules are required for binding of basic fibroblast growth factor to its high affinity receptor. Cell 64:841-849. 